\title{
What is trust?: perspectives from farmers and other experts in the field of agriculture in Africa
}

Obidimma C Ezezika ${ }^{1,2,3^{*}}$, Jessica $O h^{1}$

\begin{abstract}
Background: Agricultural biotechnology public-private partnerships (PPPs) have been recognized as necessary for improving agricultural productivity and increasing food production in sub-Saharan Africa. However, there are issues of public trust uniquely associated with PPPs involved in the development of genetically modified (GM) crops. Insight into how trust is understood by agbiotech stakeholders is needed to be able to promote and improve trust among actors comprising agbiotech PPPs. This study aimed to explore how stakeholders from the agricultural sector in sub-Saharan Africa understood the concept of trust in general as well as in the context of agbiotech PPPs.

Methods: Our data collection relied on sixty-one semi-structured, face-to-face interviews conducted with agbiotech stakeholders as part of a larger study investigating the role of trust in eight agbiotech projects across Africa. Interview transcripts were analyzed to create a narrative on how trust is understood by the study's participants.

Results: Responses to the question "what is trust?" were diverse. However, across interviewees' responses we identified six themes. In order to build and foster trust in a partnership, partners reported that one must practice integrity and honesty; deliver results in an accountable manner; be capable and competent; share the same objectives and interests; be transparent about actions and intentions through clear communication; and target services toward the interests of the public.

Conclusions: Participants reported that trust is either a very important factor or the most important factor in the making or breaking of success in agbiotech PPPs. The six themes that emerged from the interview data form a concept of trust. We thereby propose the following definition of trust in the context of agricultural biotechnology: an expectation held by an individual that the performance and behaviour of another will be supported by tangible results; facilitated by competency and transparency; grounded in a shared vision; and guided by integrity and an interest for the common good. This definition sheds light on important elements that agbiotech stakeholders believe should be present for trust to exist among members of agbiotech PPPs, for whom this definition can serve as a guide for building more effective partnerships.
\end{abstract}

\section{Background}

\section{Why public-private partnerships?}

To address rising food security concerns in sub-Saharan Africa, most countries have already started pursuing strategies that involve the application of biotechnology in the field of agriculture. There are many studies that attest to the significant potential of modern biotechnology to raise agricultural productivity, enhance food security, and

\footnotetext{
* Correspondence: obidimma.ezezika@srcglobal.org

'Sandra Rotman Centre, University Health Network and University of

Toronto, Toronto, Ontario, Canada

Full list of author information is available at the end of the article
}

contribute to alleviating poverty in developing countries $[1,2]$. One way to facilitate the implementation of agricultural biotechnology has been through public-private partnerships (PPPs) [3]. PPPs are often clusters of partners, local and foreign, that form both formal and informal coalitions and consortia to deal with challenges and opportunities [3]. Considering the specific context of agricultural biotechnology, this paper defines PPPs as any 'collaborative effort between public and private entities in which each contributes to planning, commits resources, shares risks and benefits and conducts activities to accomplish a shared object' [4]. The appeal of PPPs is

\section{(Ciomed Central}


widely perceived to include research that neither the private nor public sector may conduct independently; access to privately-owned knowledge and resources for publicgood research; new sources of funding directed to public sector research; and novel delivery mechanisms for public technologies [3]. There is widespread acknowledgment of the potential that agbiotech PPPs have for addressing food security needs in developing countries $[5,6]$.

\section{The challenge with public-private partnerships in the field of agbiotech}

Despite this great potential, however, the supposed impact of PPPs on food security is yet to be realized [1,3,7]. Most of the literature examining the constraints to successful agricultural PPPs focuses on general problems that relate to both forming partnerships between public and private actors and operating together in a partnership framework. Such problems include dissimilar working styles and reward structures, complex intellectual property rights (IPR) arrangements, and unsupportive institutional arrangements and cultures [3,8-10]. Some studies have also looked at factors exogenous to the partnerships. Muraguri [7], for example, noted that donor control of funds and the technology being supply-driven and science-led- rather than user-driven-are factors hampering the ability of agbiotech PPPs to have a positive impact on the attainment of food security in Kenya. In a survey conducted of key informants on PPPs between Consultative Group of International Agricultural Research (CGIAR) centers and multinational agricultural research firms, $40 \%$ stated that mutually negative perceptions stemming from distrust and suspicion were a primary impediment to greater partnership [4]. This finding is supported by other studies concluding that a lack of trust poses a significant challenge to the success of PPPs $[3,11,12]$. Regardless of whether these factors are endogenous or exogenous to the partnership, the noted challenges to the success of PPPs imply the incurrence of high transaction costs, as there is often no history of working together and no informal agreements between parties; protracted negotiations and complicated formal agreements must thereby be developed [3].

\section{Trust: a solution?}

Trust is the central building block of human relationships. It is also fundamental to navigating in the complexity and interdependence that characterize contemporary society [13]. Trust remains the basis of high performance, increased openness, risk taking, high levels of commitment, loyalty, and productivity - all of which are sought after by organizations [14]. Researchers believe that trust can provide a sense of security and facilitate the kind of risk taking rendered essential in contexts of high ambiguity, uncertainty and complexity [15]. Carolyn [16] postulates 'when we trust someone to do something, we let them get on with it. We don't waste time doubleinstructing and double-checking.' On the other hand, the lack of trust among individuals in any context in which human beings interact with each other can have disastrous effects: it can subvert powerful countries, bankrupt lucrative companies, destroy flourishing economies, and ruin the happiest of marriages [17]. Agricultural biotechnology PPPs are not immune to the misfortunes that ensue from a lack of trust among human beings. Like any other PPP, they must continually foster a culture of trust among members in order to be efficient, effective and of high impact. Yet, not only do the public and private sector hold mutually negative perceptions of each other [4], but public and private partners involved in agbiotech initiatives must deal with a public that is wary of the perceived risks of GM (genetically modified) crops [18] and suspicious about private sector involvement in their country $[2,19]$. Despite high levels of trust among agbiotech partners, the success of their partnership ultimately depends on public acceptance of the end product. Trust, or lack thereof, in an agbiotech PPP therefore occurs on more planes than one: between the partners, as well as between the partnership and the end user (e.g., the farmer, in the context of this study). In order to analyze the particular role(s) that trust has played in existing agbiotech initiatives and provide lessons for improving future projects, we interviewed stakeholders from diverse backgrounds with the aim of hearing their response to the seemingly simple question "what is trust?"

Trust has, however, been heterogeneously defined by scholars and practitioners in various fields and it comprises elements that are understood and ranked differently by different people. To date, there has been no universally accepted scholarly definition of trust [20], despite widespread agreement on the importance of trust [21-23]. It is widely acknowledged that trust has been difficult to define because it is a complex and multifaceted concept $[24,25]$. In individual terms, for example, trust is conceived as the extent to which people are willing to depend upon, and make themselves vulnerable to, others $[26,27]$. From an organizational view, trust is often a collective judgment that another group will not behave opportunistically, act honestly in negotiations, and make an honest effort to ensure that their actions correspond to their commitment $[28,29]$. Evidence from a contemporary, cross-disciplinary collection of scholarly writing on trust definitions suggests that certain recurring themes emerge irrespective of the context of study (i.e., philosophical, economic, organizational, or individual) [24]. In no particular order, the key elements of trust are found to be: willingness to risk vulnerability [20]; confidence [21]; benevolence [25,30,31]; reliability [32,33]; 
competence [32,34]; honesty $[24,25,27,29]$; and openness $[30,32]$. While all of these elements of trust are important, their 'relative weight will depend on the nature of the interdependence and vulnerability in the relationship' [24].

Nevertheless, because of a lack of a uniform and allencompassing definition of trust, hearing what agbiotech stakeholders had to say about the word trust became imperative in understanding how, and to what extent, they perceived trust to contribute to the failures and successes of agbiotech PPPs.

As the number of agbiotech PPPs in developing countries increases, studies inquiring ways to maximize this potential is needed. Our study attempts to fill an important gap by inquiring into the concept of trust as it relates to the particular topic of agbiotech PPPs in sub-Saharan Africa.

\section{Methods}

When developing the interview guide for this study, a definition of trust was deliberately not provided to avoid imposing any definition on the interviewees and thereby influencing the results of the study. In doing so, the aim of this study was to explore interviewees' spontaneous descriptions of trust and, specifically, their understanding of trust and the elements thereof (see Additional file 1 for sample questions from the interview guide).

Data collection consisted of semi-structured, face-toface interviews with sixty-one key informants that were drawn from eight detailed case studies, comprising a larger investigation exploring the role of trust in agbiotech PPPs, conducted in sub-Saharan Africa ${ }^{a}$ (shown below in Table 1) by researchers from the Sandra Rotman Centre. Interviewees were identified first by making a list of key individuals associated with each of the case studies based on the stakeholders identified within the research protocol. This list was then populated further through snowball sampling and through the Sandra Rotman Centre's Social Audit Project [19]. Potential interviewees were sent an invitation, which included an explanation of the case study series, to participate in the interview.

Table 1 The eight case studies on the role of trust in agbiotech initiatives in sub-Saharan Africa.

\begin{tabular}{ll}
\hline Project & Country \\
\hline Bt maize & Egypt \\
Bt cotton & Burkina Faso \\
Bt maize & South Africa \\
Insect Resistance Maize for Africa (IRMA) & Kenya \\
Bt cotton & Tanzania \\
Cowpea Improvement Project & Nigeria \\
Virus Resistant Cassava (VIRCA) & Uganda \\
Bt potato & South Africa \\
\hline
\end{tabular}

Those who consented to participate were informed that the interview would be recorded, transcribed verbatim and then analyzed. The data collected from these interviews were also supplemented by a review of the literature on PPPs, agbiotech PPPs, and trust definitions.

Interviews took place in Tanzania, Kenya, Uganda, Egypt, Burkina Faso, United States, South Africa, and Nigeria. Stakeholders from diverse backgrounds, including government representatives, private sector companies, and GM farmers, were interviewed. Data analysis was conducted by reading through the transcripts several times, identifying emerging trends and organizing them into major themes.

The interviews were conducted by Ezezika and researchers from the Sandra Rotman Centre. An external transcriber was hired to complete the transcription of all the audio files. Oh and Ezezika completed the coding of the transcripts (i.e., systematic selection of a word or phrase to reflect the participants' responses) and conducted the analysis. Codes were organized into broad categories under which sub-categories were created, along with descriptive properties, including relevant quotations.

We received Research Ethics Board (REB) approval for conducting this study from the University Health Network (UHN). Signed consent was obtained from each participant after providing information on the purpose and procedure of the study.

\section{Results and discussion}

This study assessed how stakeholders from the agricultural sector in sub-Saharan Africa defined and described trust. The lack of a universally accepted definition of trust is encapsulated in the conceptual diversity evident in the interviewees' responses to the question "what is trust?" When asked to define trust, many interviewees expressed that such a task was "difficult"- which is reflective of the "conceptual confusion" [35] that characterizes the existing literature on trust definitions. Nonetheless, most interviewees agreed that trust is either a very important factor or the most important factor when it comes to making successful agricultural biotechnology PPPs.

While interviewees' responses to the question "what is trust?" were diverse, this study identified six major themes that encapsulate the interviewees' responses (shown in Table 2).

\section{Integrity: honesty is still the best policy}

The integrity of the partner was described as being an important element determining the level of trust in the partnership. Specifically, many interviewees emphasized honesty and truthfulness as being of utmost importance in making or breaking trust in agbiotech PPPs due to the high stakes and risks implied by biotechnology. 
Table 2 Key emerging themes from interviewee responses

\begin{tabular}{|c|c|c|}
\hline Theme & & Interviewee responses per theme (\%) \\
\hline \multirow[t]{6}{*}{ Integrity } & No harm and mischief to others & 31 \\
\hline & Partners must behave with integrity & \\
\hline & Help others, especially in times of difficulty & \\
\hline & Truthful and honest in dealings with others & \\
\hline & Show sincerity in interactions with others & \\
\hline & Have long-established credibility & \\
\hline \multirow[t]{5}{*}{ Delivery } & Deliver results that are expected of you & 21 \\
\hline & Follow through on agreed upon outputs & \\
\hline & Meet appropriate deadlines & \\
\hline & Good results stemming from the product and producer [of technology] & \\
\hline & Agreements in place to ensure accountability & \\
\hline \multirow[t]{4}{*}{ Capability } & Confidence in the competency of the individual or institution & 19 \\
\hline & Have capacity to perform role(s) effectively & \\
\hline & Data provided by researchers must be science-based & \\
\hline & The technology must prove effective to the end user & \\
\hline \multirow[t]{4}{*}{ Mutuality } & Partners must have uniform vision and objectives & 14 \\
\hline & Partnership mutually beneficial to both parties & \\
\hline & Work together cooperatively & \\
\hline & Equal advantage and understanding in the partnership & \\
\hline \multirow[t]{3}{*}{ Transparency } & Full disclosure and discussion of issues pertaining to partnership & 13 \\
\hline & Not keeping secrets (i.e., doing everything on the table) & \\
\hline & Regular dissemination of information & \\
\hline Humanitarianism & Provide services on behalf of a target community & 2 \\
\hline
\end{tabular}

This emphasis was grounded in interviewees' insistence that partners involved in the project need to be honest about what they can promise and deliver, andespecially with the public-what the GM crop technology can and cannot accomplish and the potential health risks posed by the technology.

One interviewee involved in the Bt cowpea project in Nigeria, talking about trust among partners, stated: "Trust has been a key factor in developing and also enhancing my participation in the project. I expected an honest explanation of what our roles are, what do we expect out of it. So trust is very key especially as I told you in the beginning, this [Bt cowpea] is entirely a very new product in Africa." He seems to attribute his enhanced participation in the project to trust, which he in turn attributes to honesty ("honest explanation"). Similarly, a small-scale farmer of Bt cotton from Burkina Faso defined trust as "telling truth in his heart" and said that the most important element of trust is "being honest to each other." Making a direct connection between trust and honesty, an executive of Pioneer Hybrid stated, "But I think it's [trust] interlinked with honesty. You cannot be trustworthy and not be honest." Focusing specifically on GM technology, he also stated: "You must not overpromise. If you overpromise it will come across as if trying you are trying to fool the people, and it will come back to you. You must think about what the technology can and cannot do honestly." He emphasizes the danger of overpromising -in other words, exaggerating the truth-and believes that the other party must be truthful by being modest about what the technology can actually deliver. He, like many other interviewees, suggests that honesty is a prerequisite for trust - that, without it, trust cannot exist. In line with honesty, some interviewees cited sincerity as an important aspect of a partner's integrity. For example, an executive of the Donald Danforth Plant Science Centre (DDPSC) stated, "a really important aspect of trust is sincerity. If the individual is sincere, it is going to show in the interactions that happen along the way. And so there won't be misleading, there won't be excuses. There will be true efforts to try and make progress overall." This interviewee uses the words sincerity and true, which connote honesty, but also suggests that only when a partner's desire to contribute to the project is genuine will it translate to quality work that is done efficiently.

Another small-scale Bt cotton farmer from Burkina Faso describes his understanding of trust this way: "the most important element [of trust] is that when [I] give[], for example, money to someone to go and buy oxen for [me]. So [I] give him some money to buy ten oxen. So that person goes and buys the ten oxen. But now, it happens that 
the money was remaining and that guy brought back the remaining money to [me]." There are two parts to the farmer's example: bringing good results and being honest. But he uses the example of money to zero in on the idea of honesty: someone who brings back the remaining change from the money given to him for carrying out a favor is considered to be someone who is not cheating or defrauding - in other words, an honest person. A number of other interviewees used the example of lending money when describing honesty, which suggests that money is commonly used as a platform in which people test others' honesty, and in turn, trustworthiness.

Interviewees also regarded trust as providing assurance that a partner is not "up to no good" and doing "evil" and "wrong." Doubts such as these mainly pertained to concerns about the intentions of partners. For example, one interviewee posed the rhetorical question: "Why would he [anybody] want to come to Kenya with transgenic materials and not anywhere else? I would want to have trust that whatever we are doing it is safe. You are not coming to do things that are not right in the country. We need to trust that whatever you are saying that you are doing there is no mischief." This interviewee touches on ethical concerns that must be taken into consideration, but also stresses the importance of character - that individuals should not be engaging in malicious behaviour that is not legally and morally right.

\section{Good intentions and making promises are not enough:} delivering results in an accountable manner

Many interviewees considered a partner's delivery of results as crucial in determining whether they can be trusted. A small-scale farmer from Kenya put it simply: "Trust means you are shown something by somebody, for example you are told to do this by somebody and you do it." The idea of good cooperation is implied, but the focus is on the actual delivery of something that was requested. A small-scale Bt maize farmer from South Africa similarly stated that trust is "when they said that they will deliver on a certain day, that they will deliver in a certain day and they do deliver" [italics added]. This interviewee presents a delivery "trifecta": saying something, meaning it, and actually doing it - these three factors comprise a successful delivery that leads to trust.

An interviewee from the Agricultural Innovation Research Foundation (AIRF) in Tanzania said trust is "being accountable in channeling resources in areas that have been agreed and finally every participant in that project being able to give the outputs that have an impact with what has been agreed from the beginning... And mistrust would be if one of the participants in that project or grouping does otherwise from what was agreed." This interviewee touches on the idea of individuals keeping promises and carrying out, till the end, their respective roles with which everyone has agreed since the partnership's inception. This interviewee also uses the word accountable to emphasize that the delivery of results must be done in an accountable manner, according to prior agreements that have been made. An AATF member stated, "Make sure that as partners you do your own part of the bargain so that you build trust not just for this project but also future endeavors of partnerships." This interviewee stresses the importance of partners following through on their own individual contributions as promised and agreed upon, and, unlike other interviewees, also suggests that the result of doing so-an atmosphere of trust among partners-transcends the current undertaking and sets a foundation conducive to successful collaborative efforts in the future.

\section{Trust may be a social virtue but it entails hard, technical skills and knowledge}

According to our interviewees, character is important for building trust but it needs to go hand in hand with competency. For instance, a partner of the Network for the Genetic Improvement of Cowpea for Africa (NGICA) stated: "Someone may be sincere but he may not be reliable because he does not have the capacity." While this interviewee considers sincerity an important component of trust, the presence of that one quality does not render one trustworthy; regardless of how sincere one is, their lack of capability may nullify their credibility. However, many interviewees also made a direct connection between trust and capability. An interviewee involved in the Bt potato project in South Africa said that trust is about "knowing that that person has the necessary knowledge and expertise to perform them [assigned tasks] correctly." Similarly, an executive of Monsanto in Africa stated: "When institutions come together, it is about do I trust your ability to function, to be capable, and to help meet the common goals that are bringing us together. So it is a trust in your capability. Trust in your ability to deliver that is most important I think." A small-scale Bt maize farmer from South Africa said trust is when "you believe and you feel that you are in safe hands." A scientist at the Kenya Agricultural Research Institute (KARI), providing a more contextspecific description, defined capability in terms of " $\mathrm{t}]$ echnical competence and the ability to follow the laws," adding, "[e]specially for transgenics, that is very critical."

Another interviewee from the AATF linked trust to capability using an analogy: "trust is something I consider important because if you want to embark on a trip across this ocean to the other side of Dar es Salaam, you have to trust first of all the boat that you are going to take, you have to trust the engineer who is going to drive it. That is the same thing I have in my mind in terms of partnership. Each partner should be able to deliver with competence 
what he or she is supposed to do or what they said they were going to do." This interviewee emphasizes the importance of both the product and the producer - both of which must display competence in order to gain the end user's trust.

\section{The importance of sharing the same vision and mutual interests}

The idea of sharing the same vision was also frequently cited by interviewees - although each described it in a slightly nuanced way. A KARI executive believes that trust is when two organizations feel that "[they] are working towards the same objective" and further stated: ...when I think of trust, I think of like when two organizations are in a partnership, the two organizations are in a partnership for a specific purpose. And I would assume that that purpose is uniform across the two organizations. That they are seeing the same vision, they are seeing the same mission... Not that this organization is aiming in this direction but using the other organization to help them achieve their objective. This interviewee touches on the idea of a single vision bringing together partners, who are expected to assist each other in reaching like goals. In more succinct terms, but more stressing reciprocity, an executive of Monsanto in Africa stated: For me, when two institutions come together, they are coming together because it is mutually beneficial for them and for the project and the outcome that they are trying to achieve.

To an AATF member, however, partners who share anything in common are simply able to work well together. This interviewee stated: I think it [trust] is just like human beings. We have to have something common right from the beginning. Like I said when we approached some of these institutions, already they had some of these programs. They already understood biotechnology. So it makes it easier to work with them. Another AATF member equated trust with the sharing of the same dreams and goals and said, "if you are going into any partnership with someone, it is expected that the partnership or whatever relationship that you have had is based on trust in the first instance. Because the person trusts that you share the same dreams, you share the same goals, aspirations and you have plans to achieve the same targets."

\section{Transparency must be practiced when the subject at hand is a controversial one}

Many interviewees' disapproval of secretive activity and dishonesty coincided with their listing transparency as an important element of trust. An executive of the Programme for Biosafety Systems (PBS) described trust this way: "if you get bad results, you will still report them. Communicate freely. Communicate is almost part of transparency but it is also important in its own right." Aside from mentioning communication and transparency, this interviewee also touches on the importance of having the courage to do the right thing-reporting bad resultseven if it may be difficult (e.g. damaging to reputation). A member of KARI, describing his understanding of trust between parties in general, stated: "[in a relationship of trust] there are not other motives, no hidden agendas, it is an open relationship where the agendas are put on the table and one partner does not hide some things, there is not smokescreen or something like that." Also in favour of an open and transparent environment was an executive of CSIR in Pretoria, among others, who stated that trust is having confidence that "both partners will disclose what they need to disclose to each other and not keep secrets from each other."

A researcher at the Institut de l'Environnement et de Recherche Agricoles (INERA), stressing the importance of "doing things based on trust," said: This is our philosophy. Tell the farmer what we are doing, why we are doing what we are doing and the way we are doing it. And having him to tell us what is good for him, what is not good for him. And after that I think the next step will simply come normally. This interviewee talks about upholding transparent practices on both ends: not only must project partners be open and clear about their roles, intentions, and methods but it is expected that the farmer must also be open about their feelings and views about the project. According to this interviewee, this mutual transparency will naturally lead to "the next step": trust.

Transparency involves sharing information and operating in such a way that others can easily see what activities are executed. It is no surprise that many interviewees cited transparency as an important element of trust; lack of transparency can lead to even more suspicion and doubt when the subject-GM technology-of the project being pursued is controversial that it already warrants such an atmosphere to exist.

\section{Humanitarian goals and actions: services must benefit the community}

One view that emerged as unique from the interviewee responses was that "trust" means providing services or doing good on behalf of a target community. This theme emerged from two interviewees. One interviewee stated, "[my understanding of trust is that] you are credible and you are working for the interests of the public." The other interviewee stated: Trust is an arrangement where you provide services and provide leadership on behalf of a target community.... Like even the Bill and Melinda Gates Foundation I could call a trust because they don't make profits but they contribute towards the welfare of the needy. And that means they are not having a group of profit makers; it is not a company geared towards profit making or an arrangement towards making funds. But it is there purposely to provide services and good on behalf 
of the target group they are acting for. So it can be as broad as possible. But we can narrow it to a specific trust. This interviewee perceives trust to be an arrangement in which there is a clear beneficiary: the community. We understand these views to stem from the belief that the purpose of agriculture biotechnology is less about profitmaking than about contributing to the public's wellbeing. While the responses of these two interviewees may seem to overlap with other responses from this study's participants, we placed them in a standalone theme because of their emphasis on the beneficiary being the public or community.

\section{Describing trust: implications for agbiotech programs}

The themes emerging from the interviewee responses form a concept of trust that is consistent with theories and understandings of trust articulated in various disciplines in the literature $[24,29,33,35]$. The cited elements of trust, which constitute the six emerging themes, are: honesty, delivery, capability, shared vision, transparency, and humanitarianism. The importance that interviewees assigned to competence, honesty and openness [as elements of trust] is clearly supported by the literature. However, the interviewees also emphasized the concept of delivery as a core element of trust. In other words, honesty and integrity are not sufficient for building trust; partners must also see results, follow through on agreed upon outputs, and meet appropriate deadlines. Interviewees also emphasized that partners must converge towards a shared vision of the partnership and its objectives in order to have trust in one another. The elements delivery and shared vision are not explicitly cited in the literature as core elements of trust although delivery is encompassed in the commonly agreed upon element reliability. We believe these two were cited by interviewees as elements to emphasize their high relevance to agbiotech PPPs. Moreover, considering that our eight case studies provided the context in which our interviewees described and defined trust, we understand the particular elements [of trust] cited by the interviewees to be of particular relevance to agbiotech PPPs. Based on the interviewee responses, we have developed the following definition of trust: an expectation held by an individual or organization that the performance and behaviour of another will be supported by tangible results; facilitated by competency and transparency; grounded in a shared vision; and guided by integrity and an interest for the common good (see Figure 1 for a graphic conveying our definition of trust).

This description of trust provides valuable insight into what it means to be trustworthy in the eyes of agricultural biotechnology partners and members of the public who have a stake in the fate of agbiotech PPPs. Second, despite the lack of a simple metric that is able to capture the complexity and subjectivity that characterizes trust, this definition can be used by PPPs as a framework or checklist to determine the presence of the elements comprising this definition to assess the general level (e.g., nonexistent, very low, low, high, or very high) of trust within the partnership. Furthermore, this description can help tailor regulations, standards and practices for PPPs in ways that give rise to the elements that interviewees deemed important for facilitating trust in agricultural biotechnology partnerships.

This definition can precisely guide a partnership organization on how to institutionalize transparency in its policies so there is a standard system dictating how information should be shared and how partners will be held accountable. The result is not only enhanced collaboration and trust among partners, but more trust won from farmers, investors, the media, and government important actors that all have an impact on the success of an agbiotech PPP. In a similar vein, this description of trust based on the results of this study can provide guidance on how to enhance implementation mechanisms and provide impetus for PPPs to emphasize the importance of having well-defined performance benchmarks to ensure that the displayed potential and qualifications on which a partner was initially hired are consistently translated into quality work.

This definition also underscores the fact that members in a partnership, despite their level of competency, will be unable to work together effectively if not bound by a shared vision of the partnership's goals and objectives the identification and implementation of which must be done collectively to ensure that member input leads to outputs that are beneficial to all partners.

\section{Conclusion}

The central aim of this paper has been to show how stakeholders in the agricultural sector in sub-Saharan Africa understand the function of trust in the successes and drawbacks faced by partners in agbiotech PPPs in order to shed light on how such partnerships can be improved. We found that the interviewees' responses revolved around six key emerging themes, each of which encompasses elements of trust that the interviewees believe are important. There is already widespread recognition that PPPs are an essential component in the advancement of biotechnology in developing countries, and especially in sub-Saharan Africa. While acknowledging that no blueprint exists for making successful agbiotech PPPs, we have produced a description of trust encapsulating the results of this study as an attempt to shed light on how the presence of trust among partners, and between partners and the public, can maximise the potential of PPPs in sub-Saharan Africa. 


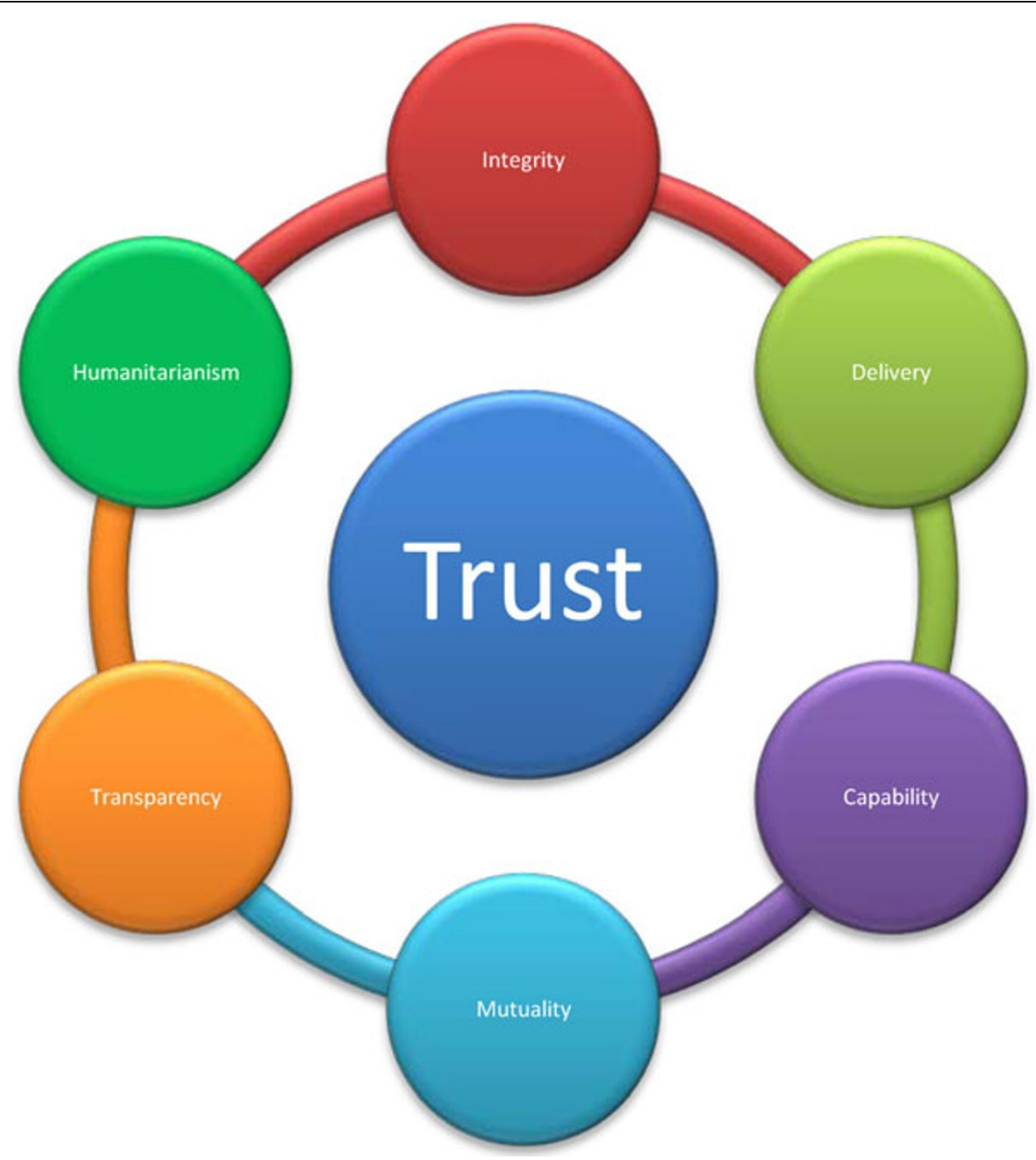

Figure 1 Stakeholders' understanding of trust. Summary of interviewee responses. This graphic emphasizes the importance of the central idea, trust, as well as how the themes comprising the outer ring represent elements that lead to the manifestation of trust. The interviewee responses are captured in six emerging themes, which, in order of frequency, were: integrity, delivery, capability, mutuality, transparency, and humanitarianism. Yet, as many interviewees stated, these elements [of trust] are not mutually exclusive; instead, they are interconnected and often depend on each other to exist and, in turn, contribute to the manifestation of trust.

\section{Endnotes}

${ }^{a}$ The case of Bt maize in Egypt was an exception that was included in this series of case studies because Egypt was the first country in North Africa to have commercialized a GM crop.

\section{Additional material}

\section{Additional file 1: Sample questions from the interview guide.}

\section{Acknowledgements}

The authors are grateful to each of the participants who contributed substantial time and effort to this study. The authors also thank Claudia Emerson and Jocalyn Clark for comments on earlier drafts of the manuscript.
This project was funded by the Bill \& Melinda Gates Foundation and supported by the Sandra Rotman Centre, an academic centre at the University Health Network and University of Toronto. The findings and conclusions contained within are those of the authors and do not necessarily reflect official positions or policies of the foundation.

This article has been published as part of Agriculture \& Food Security Volume 1 Supplement 1, 2012: Fostering innovation through building trust: lessons from agricultural biotechnology partnerships in Africa. The full contents of the supplement are available online at http://www.

agricultureandfoodsecurity.com/supplements/1/S1. Publication of this supplement was funded by the Sandra Rotman Centre at the University Health Network and the University of Toronto. The supplement was devised by the Sandra Rotman Centre.

\section{Author details}

'Sandra Rotman Centre, University Health Network and University of Toronto, Toronto, Ontario, Canada. ${ }^{2}$ African Centre for Innovation and Leadership Development, Federal Capital Territory, Abuja, Nigeria. ${ }^{3}$ Dalla Lana School of Public Health, University of Toronto, Toronto, Canada. 


\section{Authors' contributions}

Study conception and design: OCE. Data collection: OCE. Analysis and interpretation of data: JO and OCE. Draft of the manuscript: JO and OCE. Critical revision of the manuscript for important intellectual content: OCE and JO. All authors read and approved the final manuscript.

\section{Competing interests}

The authors declare that they have no competing interests.

Published: 1 November 2012

\section{References}

1. Spielman D: Pro-poor agricultural biotechnology: Can the international research system deliver the goods? Food Policy 2007, 32:189-204.

2. Byerlee D, Fischer K: Accessing Modern Science: Policy and Institutional Options for Agricultural Biotechnology in Developing Countries. Wolrd Development 2002, 30(6):931-948.

3. Hall A: Public-private sector partnerships in an agricultural system of innovation: concepts and challenges. International Journal of Technology and Management and Sustainable Development 2006, 5(1).

4. Spielman DJ, Grebmer K: Public-Private Partnerships in International Agricultural Research: An Analysis of Constraints. Journal of Technology Transfer 2006, 31:291-300.

5. Hall A, Sivamohan M, Clark N, Taylor S, Bockett G: Institutional developments in Indian agricultural R\&D systems: the emerging patterns of public and private sector activity. Science Technology \& Development 1998, 16:51-76.

6. Hall A, Bockett G, Taylor S, Sivamohan M, Clark N: Why research partnerships really matter: innovation theory, institutional arrangements and implications for developing new technology for the poor. World Development 2001, 29(5):783-797.

7. Muraguri L: Unplugged!: An analysis of agricultural biotechnology PPPs in Kenya. Journal of International Development 2010, 22:289-307.

8. Spielman DJ, Grebmer K: Public-private partnerships in agricultural research: an analysis of challenges facing industry and the Consultative Group on international agricultural research. EPTD Discussion Paper No. 113 International Food Policy Research Institute; 2004.

9. Hartwich F, Janssen W, Tola J: Public-private partnerships for agroindustrial research: recommendations from an expert consultation. ISNAR Briefing Paper No.16 2003.

10. Byerlee $D$, Echeverria R: Agricultural research policy in an era of privatization. Oxon and New York: CABI Publishing; 2002.

11. De Costa A, Johansson E, Diwan V: Barriers of Mistrust: Public and Private Health Sectors' Perceptions of Each Other in Madhya Pradesh, India. Qualitative Health Research 2008, 18(6):756-766.

12. Edelenbos J, Klijn E: Trust in Complex Decision-Making Networks: A Theoretical and Empirical Exploration. Administration \& Society 2007, 39(1):25-50

13. Brewer $B$, Hayllar M: Building public trust through public-private partnerships. International Review of Administrative Sciences 2005, 71(3):475-492.

14. Semerciöz F, Hassan M, Aldermir Z: An Empirical Study on the Role of Interpersonal and Institutional Trust in Organizational Innovativeness. International Business Research 2011, 4(2):125-136.

15. Six F: The Trouble with Trust: The Dynamics of Interpersonal Trust Building. UK: Edgar Elgar Cheltenham; 2005.

16. Carolyn L: Driving productivity, engagement and innovation by building trust. Human Resources Magazine 2009, 13(5):24-26.

17. Covey S: The Speed of Trust: The One Thing That Changes Everything. New York: Free Press; 2006.

18. Peterson R: Public perceptions of agricultural biotechnology and pesticides: Recent understandings and implications for risk communication. American Entomology 2000, 46:8-16.

19. Ezezika OC, Thomas F, Lavery JV, Daar AS, Singer PA: A Social Audit Model for Agro-biotechnology Initiatives in Developing Countries: Accounting for Ethical, Social, Cultural and Commercialization Issues. Journal of Technology Management and Innovation 2009, 4(3):24-33.

20. Rousseau D, Sitkin S, Burt R, Camerer C: Not so different after all: A crossdiscipline view of trust. Academy of Management Review 1998, 23:393-404.
21. Kee H, Knox R: Conceptual and methodological considerations in the study of trust and suspicion. Journal of Conflict Resolution 1970, 14:357-366.

22. Yamagishi T, Yamagishi M: Trust and commitment in the United States and Japan. Motivation and Emotion 1994, 18(2):129-166.

23. Cvetkovich G, Löfstedt $R$ : Social trust and the management of risk. London: Earthscan; 1999.

24. Tschannen-Moran M, Hoy W: A multidisciplinary analysis of the nature, meaning, and measurement of trust. Review of Educational Research 2000, 70(4):547-593.

25. Hoy W, Tschannen-Moran M: Five faces of trust: An empirical confirmation in urban elementary schools. Journal of School Leadership 1999, 9:184-208.

26. Frost T, Stimpson D, Maughan M: Some correlates of trust. Journal of Psychology 1978, 99:103-108.

27. Rotter J: A new scale for the measurement of interpersonal trust. Journal of Personality 1967, 35(651):665.

28. Bradach J, Eccles R: Price, authority, and trust: From ideal types to plural forms. Annual Review of Sociology 1989, 15(97):118.

29. Cummings L, Bromily P: The Organizational Trust Inventory (OTI): Development and validation. In Trust in organizations. Thousand Oaks, CA.: Thousand Oaks, CA;Kramer R, Tyler T 1996:302-330.

30. Mishra A: Organizational responses to crisis: The centrality of trust. In Trust in organizations. Thousand Oaks, CA.: Sage;Kramer R, Tyler T 1996:261-287.

31. Zand D: Trust and managerial problem solving. Administrative Science Quarterly 1971, 17:229-239.

32. Butler J, Cantrell R: A behavioral decision theory approach to modeling dyadic trust in superiors and subordinates. Psychological Reports 1984, 55(81):105.

33. Hosmer $\mathrm{L}$ : Trust: The connecting link between organizational theory and philosophical ethics. Adademy of Management Review 1995, 20:379-403.

34. Baier A: Trust and antitrust. Ethics 1986, 96:231-260.

35. Lewis JD, Weigert AJ: Trust as a social reality. Social Forces 1985 , 63(4):967-985.

doi:10.1186/2048-7010-1-S1-S1

Cite this article as: Ezezika and Oh: What is trust?: perspectives from farmers and other experts in the field of agriculture in Africa. Agriculture \& Food Security 2012 1(Suppl 1):S1.

\section{Submit your next manuscript to BioMed Central and take full advantage of:}

- Convenient online submission

- Thorough peer review

- No space constraints or color figure charges

- Immediate publication on acceptance

- Inclusion in PubMed, CAS, Scopus and Google Scholar

- Research which is freely available for redistribution

Submit your manuscript at www.biomedcentral.com/submit
C Biomed Central 